\section{Effect of Nitric Oxide on Seed Germination and Dormancy in Empress Trees}

\author{
Jia Liu, Tingting Xue, and Yongbao Shen ${ }^{1}$
}

\begin{abstract}
ADDITIONAL INDEX WORDS. imbibition, NO scavenger, sodium nitroprusside
Summary. Freshly harvested empress tree (Paulownia elongata) seeds have physiologic dormancy. The aim of this study was to investigate the effects of exogenous and endogenous nitric oxide (NO) on the dormancy and germination of empress tree seeds. After treatment with different concentrations of sodium nitroprusside (an NO-releasing compound) solution, the germination percentage of seeds under $12 \mathrm{~h}$ of continuous light was significantly greater. Seed germination percentage was promoted significantly by $10^{-4} \mathrm{M}$ sodium nitroprusside plus cold stratification compared with seeds treated with cold stratification only. At different hours during imbibition, empress tree seeds treated with 2-(4-carboxyphenyl)-4, 4, 5, 5- tetramethylimidazoline -1-oxyl-3-oxide potassium salt (c-PTIO), NG-nitro-Larginine methyl ester (L-NAME), and sodium tungstate showed reduced seed germination percentages. During the early hours of imbibition, c-PTIO or sodium tungstate treatment inhibited seed germination significantly. The results showed that both exogenous and endogenous NO can release empress tree seed dormancy. Endogenous NO oxide was involved in dormancy release and germination of seeds during the early stages of imbibition. Wider application of NO may be used for breaking seed dormancy in other species.
\end{abstract}

$\mathrm{E}$ mpress trees are native to China. It is mainly found in the lowelevation regions of Anhui, Hebei, Henan, Hubei, Jiangsu, Shaanxi, Shandong, and Shanxi Provinces. Empress trees have significant economic and ornamental value because of its fast growth rate, the quality of its timber (Jiménez et al., 2005; López et al., 2011; Melhuish et al., 1990), its attractive flowers, and its high nitrogen levels, which allow it to serve as a fertilizer and as fodder (Zhu et al., 1986). Empress tree seeds are light-induced seeds with physiologic dormancy, and their dormancy can be broken by gibberellic acid $\left(\mathrm{GA}_{3}\right)$, cold stratification, and dry storage (Liu et al., 2017). We have tested the seed germination of three species of Paulownia [empress tree, princess tree $(P$.

Received for publication 17 Dec. 2018. Accepted for publication 25 Feb. 2019.

Published online 6 May 2019.

College of Forestry, Nanjing Forestry University, Nanjing 210037, China; and Co-Innovation Center for Sustainable Forestry in Southern China, Nanjing Forestry University, Nanjing 210037, China

We thank the Priority Academic Program Development of Jiangsu Higher Education Institutions (PAPD) for financial assistance.

${ }^{1}$ Corresponding author. E-mail: ybshen@njfu.edu.cn.

This is an open access article distributed under the CC BY-NC-ND license (https://creativecommons.org/ licenses/by-nc-nd/4.0/).

https://doi.org/10.21273/HORTTECH04250-18 tomentosa), and foxglove tree (P. fortunei)] harvested in Nanjing, China. The germination of freshly harvested seeds in princess trees and foxglove trees was more than $85 \%$, but that of empress tree seed was only $0 \%$ to $50 \%$. Breaking seed dormancy and increasing germination of empress trees are important for production and breeding.

$\mathrm{NO}$ is a signal molecule involved in physiologic processes (Delledonne, 2005; Lamotte et al., 2005; RomeroPuertas et al., 2004). NO induces seed germination in the absence of red light (Beligni and Lamattina, 2000), breaks seed dormancy, and affects growth (Beligni and Lamattina, 2001; Durner and Klessig, 1999). Giba et al. (1998) suggested the involvement of NO in the phytochromecontrolled germination of princess tree seeds by using different $\mathrm{NO}$ releasing compounds and appropriate controls. A rapid accumulation of NO induces an equally rapid decrease in abscisic acid and promotes $\mathrm{GA}_{3}$ biosynthesis in arabidopsis (Arabidopsisthaliana) seeds (Debeaujon and Koornneef, 2000; Liu and Zhang, 2009; Liu et al., 2010).

Plants mainly produce endogenous NO through nitric oxide synthase (NOS), nitrate reductase (NR), xanthine oxidoreductase, horseradish peroxidase, and other enzymatic pathways as well as through the nitrification/denitrification cycle via reduction of nitrate and nitrogen dioxide (del Río et al., 2004).

In this study, seeds were treated with sodium nitroprusside (an NOreleasing compound) to investigate the effects of exogenous $\mathrm{NO}$ on dormancy and germination of empress tree seeds to determine whether NO-releasing compounds can be used to break seed dormancy. c-PITO [a direct NO scavenger (Bethke et al., 2004)], L-NAME (a nonselective inhibitor of NO synthase, and sodium tungstate [a specific NR inhibitor (Rockel et al., 2002)] were used at different hours during imbibition to investigate the effects of endogenous NO on seed dormancy and germination.

\section{Materials and methods}

Seeds were collected from empress trees in Nanjing Couple Park, Jiangsu Province, in eastern China on 11 Dec. 2015. Immediately after collection, seeds were separated by hand and dried in a dry and well-ventilated room for $48 \mathrm{~h}$. The water content was $12 \%$ to $13 \%$ (based on fresh weight), which was determined gravimetrically based on three replicates of $2 \mathrm{~g}$ seed by weighing them before and after drying at $103{ }^{\circ} \mathrm{C}$ for at 24 to $36 \mathrm{~h}$.

The dried seeds were stored in the dark at 15 to $25^{\circ} \mathrm{C}$ in brown paper bags for $10 \mathrm{~d}$, and the relative humidity ranged from $40 \%$ to $70 \%$. The dormant seeds were then used in experiments related to exogenous NO. Seed viability, as evaluated by tetrazolium tests (Association of Official Seed Analysts, 2010) was 97\%; two replicates of 100 seeds were used $\%$. The remaining seeds were kept in dry storage in the same conditions for

\begin{tabular}{llll}
\hline $\begin{array}{l}\text { Units } \\
\begin{array}{l}\text { To convert U.S. to SI, } \\
\text { multiply by }\end{array}\end{array}$ & U.S. unit & SI unit & $\begin{array}{l}\text { To convert SI to U.S., } \\
\text { multiply by }\end{array}$ \\
\hline 29.5735 & $\mathrm{fl} \mathrm{oz}$ & $\mathrm{mL}$ & 0.0338 \\
0.0929 & $\mathrm{ft}^{2}$ & $\mathrm{~m}^{2}$ & 10.7639 \\
28.3495 & $\mathrm{oz}$ & $\mathrm{g}$ & 0.0353 \\
$\left({ }^{\circ} \mathrm{F}-32\right) \div 1.8$ & ${ }^{\circ} \mathrm{F}$ & ${ }^{\circ} \mathrm{C}$ & $\left({ }^{\circ} \mathrm{C} \times 1.8\right)+32$
\end{tabular}


4 months; seed dormancy was released during storage, and the seeds were used in the experiments related to endogenous NO. Seed viability was $96 \%$.

ExOgENOUS NO AND LIGHT TREATMENT. Seeds dry-stored for 10 $\mathrm{d}$ were placed on petri dishes filled with a double layer of filter paper (Whatman-Xinhua Filter Paper Co., Zhejiang, China). Filter paper was wetted with $5 \mathrm{~mL} 0,10^{-6}, 10^{-5}, 10^{-4}$, $10^{-3}, 10^{-2}$, or $10^{-1} \mathrm{M}$ sodium nitroprusside (Xiya Chemical Industry Co., Shandong, China) and carbonyl prussiate $\left\{\mathrm{K}_{3}\left[\mathrm{Fe}(\mathrm{CN})_{5}(\mathrm{CO})\right]\right\}$, as a control. $\mathrm{K}_{3}\left[\mathrm{Fe}(\mathrm{CN})_{5}(\mathrm{CO})\right]$ was prepared according to Giba et al. (1998). This molecule contains, in the inner ligand sphere as the sixth ligand, isoelectric carbon monoxide instead of the nitrosonium ion (Giba et al., 1998).

Filter paper in each petri dish was moistened with $5 \mathrm{~mL}$ solution. The dishes were wrapped in aluminum foil and placed at $25^{\circ} \mathrm{C}$ in darkness for $12 \mathrm{~h}$, and then the dishes were placed in continuous light, dark, or $12 \mathrm{~h}$ light. The intensity of the light-emitting diode lamp was $15 \mu \mathrm{mol} \cdot \mathrm{m}^{-2} \cdot \mathrm{s}^{-1}$. Seeds were germinated at $25^{\circ} \mathrm{C}$ in an incubator (Liu et al., 2017). Three replications of 100 seeds were used for each treatment and 8400 seeds were used.

EXOGENOUS NO AND COLD STRATIFICATION TREATMENT. Seeds dry-stored for $10 \mathrm{~d}$ were placed on petri dishes filled with a double layer of filter paper wetted with $10^{-4} \mathrm{M}$ sodium nitroprusside solution, $10^{-4}$ $\mathrm{M} \mathrm{K}_{3}\left[\mathrm{Fe}(\mathrm{CN})_{5}(\mathrm{CO})\right]$ solution, and distilled water; and were stratified for $0,24,48,72$, and 96 h at $4^{\circ} \mathrm{C}$. After stratification, seeds were transferred to filter paper wetted with distilled water and germinated at $25{ }^{\circ} \mathrm{C}$ in continuous light. Three replications of 100 seeds were used for each treatment and 4500 seeds were used.

Treatment with c-PTIO, L-NAME, OR SODIUM TUNGSTATE. Seeds dry-stored for 4 months were placed on petri dishes filled with a double layer of filter paper wetted with $2.5 \mathrm{~mL}$ distilled water and allowed to absorb water for $0,1,2$, $3,6,9$, or $12 \mathrm{~h}$ in the dark at $25^{\circ} \mathrm{C}$. Then, $2.5 \mathrm{~mL} 0.4 \mathrm{~mm}$ c-PTIO (Skyrun Industrial Co., Zhejiang, China), $2.5 \mathrm{~mL} 2 \mathrm{M} \mathrm{L}-\mathrm{NAME}$ (Biolab Co., Beijing, China), or $2.5 \mathrm{~mL} 10 \mathrm{M}$ sodium tungstate (Shanghai Chengshao Biological Technology Co., Shandong, China) were added. The three solutions-0.2 M c-PTIO, $1 \mathrm{M}$ L-NAME, and $5 \mathrm{M}$ sodium tungstatewere applied to treat the seeds, respectively. A distilled water treatment was used as a control. Before light treatment, the total imbibition time was $12 \mathrm{~h}$ in the dark. Seeds were then germinated in continuous light at $25^{\circ} \mathrm{C}$. Three replications of 100 seeds were used for each treatment and 6300 seeds were used.

Seed Germination. After the seeds were placed in the incubator and germinated, distilled water was supplemented once every $3 \mathrm{~d}$, and the number of germinated seeds was counted every $7 \mathrm{~d}$. The germination standard was reached when radicles broke through the seedcoat, and the experiment ended on day 28 .

Data Analysis. Statistical analyses of the germination data were performed with SPSS (version 19.0; IBM Corp., Armonk, NY) for Windows software. Data were subjected to one-way analysis of variance and means were compared using the
Tukey test, considering $\alpha=0.05$. Residue normality and variance homogeneity were tested previously. The data were transformed to arcsine $\sqrt{\frac{p}{100}}$ before analysis.

\section{Results}

E F F E C T S O F S O D I U M NITROPRUSSIDE ON SEED DORMANCY AND GERMINATION IN EMPRESS TREES. The seeds of empress trees that experienced $10 \mathrm{~d}$ of dry storage had deep dormancy (Table 1). With $12 \mathrm{~h}$ of light, none of the seeds treated with distilled water and different concentrations of $\mathrm{K}_{3}\left[\mathrm{Fe}(\mathrm{CN})_{5}(\mathrm{CO})\right]$ germinated, and seeds treated with $10^{-6}$ and $10^{-5} \mathrm{M}$ sodium nitroprusside solution also did not germinate. However, after being treated with $10^{-4}, 10^{-3}$, and $10^{-2} \mathrm{M}$ sodium nitroprusside, the seed germination percentage was significantly $(P<0.05)$ greater, reaching $9 \%, 15 \%$, and $39 \%$, respectively. The optimal concentration of sodium nitroprusside was $10^{-2} \mathrm{M} ; 10^{-1} \mathrm{M}$ sodium nitroprusside solution inhibited germination, and the germination percentage was $0 \%$.

Under continuous light conditions, the germination percentage of seeds treated with distilled water or $\mathrm{K}_{3}\left[\mathrm{Fe}(\mathrm{CN})_{5}(\mathrm{CO})\right]$ was less than $2 \%$, and there was no significant difference among the $\mathrm{K}_{3}\left[\mathrm{Fe}(\mathrm{CN})_{5}(\mathrm{CO})\right]$ treatments at various concentrations (Table 1). The $10^{-6}-\mathrm{M}$ sodium nitroprusside solution promoted seed germination; the germination percentage was $7 \%$ The $10^{-2}-\mathrm{M}$ sodium nitroprusside solution had the strongest treatment effect and resulted in the greatest germination percentage, which reached $56 \%$. When the

Table 1. Germination percentage after $12 \mathrm{~h}$ and continuous light at $25^{\circ} \mathrm{C}\left(77.0{ }^{\circ} \mathrm{F}\right)$ of empress tree seeds dry-stored for 10 $\mathrm{d}$ and treated with different concentration of sodium nitroprusside and carbonyl prussiate. Germinated seeds were collected from the incubator on day 28.

\begin{tabular}{|c|c|c|c|c|}
\hline \multirow[b]{3}{*}{ Concn (M) } & \multicolumn{4}{|c|}{ Germination rate $(\% ; \text { mean } \pm S E)^{\mathrm{z}}$} \\
\hline & \multicolumn{2}{|c|}{$12 \mathrm{~L}$ light } & \multicolumn{2}{|c|}{ Continuous light } \\
\hline & Sodium nitroprusside & Carbonyl prussiate & $\overline{\text { Sodium nitroprusside }}$ & Carbonyl prussiate \\
\hline $10^{-2}$ & $39 \pm 2.65 b^{y}$ & $0 \pm 0$ & $56 \pm 3.48 \mathrm{a}$ & $1 \pm 0.58 \mathrm{~g}$ \\
\hline $10^{-3}$ & $15 \pm 0.88 \mathrm{de}$ & $0 \pm 0$ & $41 \pm 2.52 b$ & $1 \pm 0.33 \mathrm{~g}$ \\
\hline $10^{-4}$ & $9 \pm 1.76$ ef & $0 \pm 0$ & $21 \pm 1.20 \mathrm{~cd}$ & $2 \pm 0.58 \mathrm{~g}$ \\
\hline 0 & $0 \pm 0$ & $0 \pm 0$ & $2 \pm 0.33 \mathrm{~g}$ & $2 \pm 0.33 \mathrm{~g}$ \\
\hline
\end{tabular}

${ }^{z}$ The data are means of three replicates.

y Data were analyzed by one-way analysis of variance and Tukey tests. The same letters show no significance at $P=0.05$. 
concentration of sodium nitroprusside solution was too high, germination was inhibited (germination percentage, $0 \%$ ).

The $10^{-4}-\mathrm{M}$ sodium nitroprusside and $\mathrm{K}_{3}\left[\mathrm{Fe}(\mathrm{CN})_{5}(\mathrm{CO})\right]$ treatments were applied separately to empress tree seeds that had been stratified for different lengths of time and were then germinated under continuous light. Cold stratification promoted empress tree seed germination (Fig. 1). After $24,48,72$, and 96 h of stratification, the seed germination percentage increased from $2 \%$ to $4 \%, 11 \%, 19 \%$, and $23 \%$, respectively. Compared with the seed germination percentage in the stratification treatments, there was no significant difference in the seed germination percentage in the stratification plus $\mathrm{K}_{3}\left[\mathrm{Fe}(\mathrm{CN})_{5}(\mathrm{CO})\right]$ treatments. Compared with the seed germination percentage in the stratification treatments, the seed germination percentage in the cold stratification plus sodium nitroprusside treatments increased significantly from $4 \%, 11 \%$, $19 \%$, and $23 \%$ to $22 \%, 42 \%, 69 \%$, and $82 \%(P<0.05)$, respectively.

EfFects OF NO scavengers AND SYNTHETIC INHIBITORS ON DORMANCY AND GERMINATION OF EMPRESS TREE SEEDS. The effect of c-PTIO, an NO scavenger, on the germination of empress tree seeds after 4 months of dry storage was greatly reduced compared with the germination percentage of control seeds $(83 \%)$ (Fig. 2). After 0 to $6 \mathrm{~h}$ imbibition, the NO scavenger c-PTIO was added, and germination was inhibited significantly $(P<0.05)$. The earlier c-PTIO was added, the stronger the inhibitory effect. For dried seeds soaked directly with c-PTIO solution, the germination percentage was only $32 \%$. When cPTIO was added $6 \mathrm{~h}$ after imbibition, the germination percentage of the seeds was $64 \%$, which was significantly greater than the germination of seeds treated with c-PTIO soaked for 0 to $2 \mathrm{~h}$. There was no significant difference in germination percentage between seeds treated with c-PTIO by soaking for 9 to $12 \mathrm{~h}$ compared with the control.

After soaking for $0 \mathrm{~h}$ with sodium tungstate (i.e., direct soaking of the dried seeds with sodium tungstate solution), the germination of empress tree seeds was inhibited significantly $(P<0.05)$. In addition, the seed germination percentage declined from $83 \%$ to $20 \%$ (Fig. 2). After 3 and $12 \mathrm{~h}$

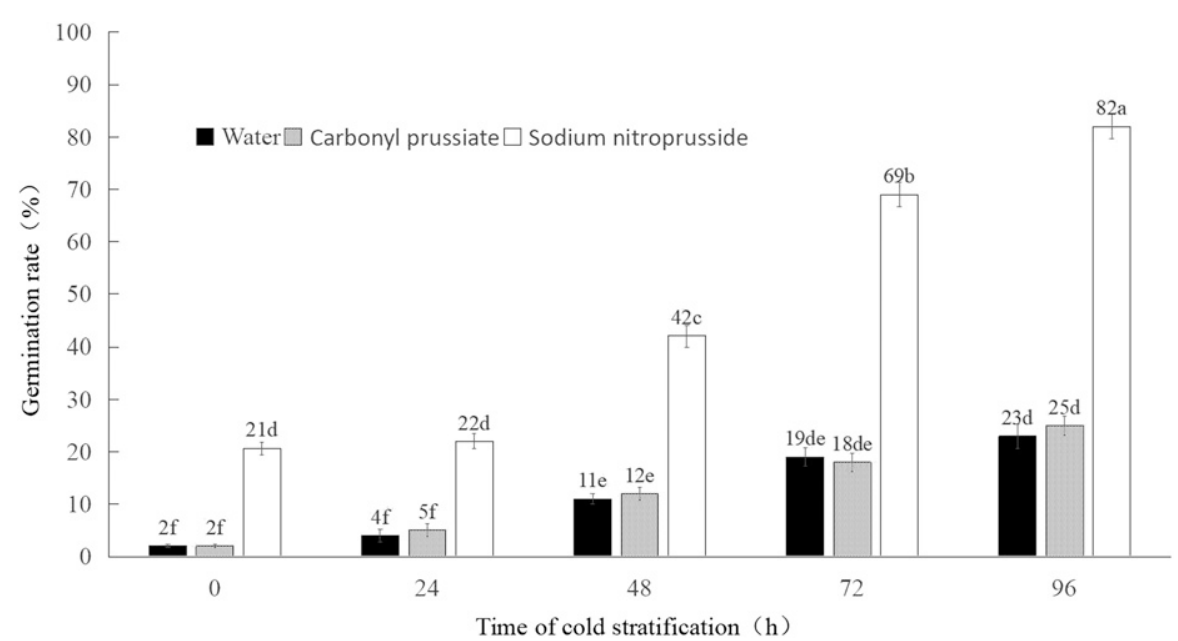

Fig. 1. Germination percentage in continuous light at $25^{\circ} \mathrm{C}\left(77.0{ }^{\circ} \mathrm{F}\right)$ of empress tree seed dry-stored for $10 \mathrm{~d}$, treated with sodium nitroprusside and carbonyl prussiate $\left\{\mathrm{K}_{3}\left[\mathrm{Fe}(\mathrm{CN})_{5}(\mathrm{CO})\right]\right\}$ followed by cold stratification for different lengths of time. Germinated seeds were collected on day 28. Data were analyzed by two one-way analyses of variance and Tukey's test. Data with the same letter are not significantly different at $\boldsymbol{P}=\mathbf{0 . 0 5}$; error bars $= \pm \mathrm{SE}$.

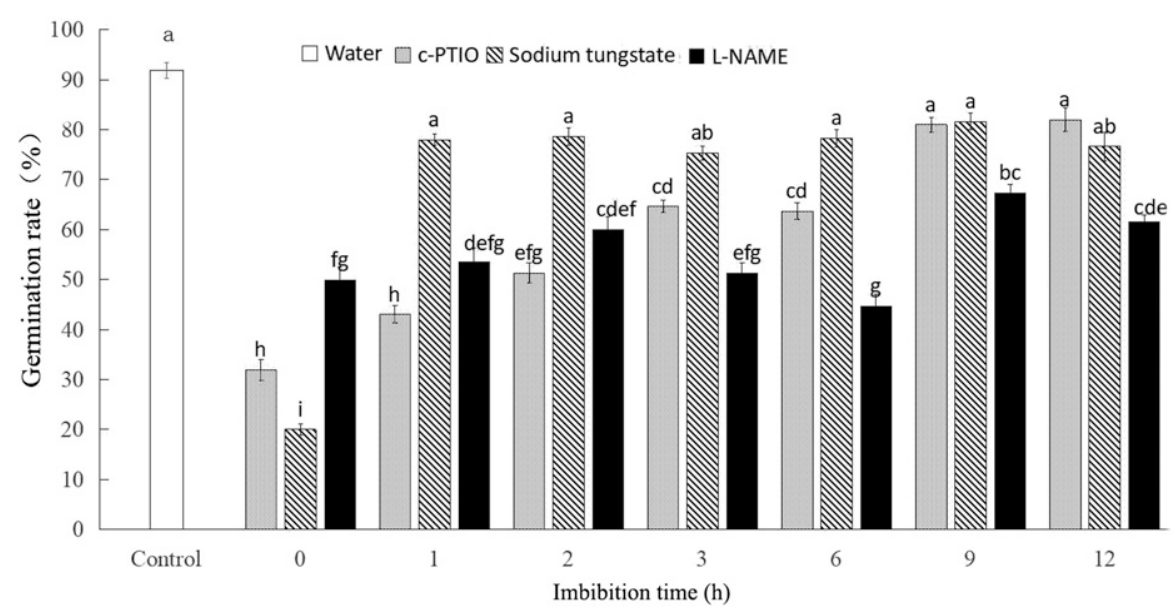

Fig. 2. Germination percentage in continuous light at $25^{\circ} \mathrm{C}\left(77.0{ }^{\circ} \mathrm{F}\right)$ of empress tree seed dry-stored for 4 months, and treated with 2-(4-carboxyphenyl)-4, 4, 5, 5-tetramethylimidazoline-1-oxyl-3-oxide potassium salt (c-PTIO), sodium tungstate, or NG-nitro-L-arginine methyl ester (L-NAME) at different imbibition times. Germinated seeds were collected on day 28. Data were analyzed by one-way analysis of variance and Tukey's test. Data with the same letter are not significantly different at $P=0.05$; error bars $= \pm \mathrm{SE}$.

of imbibition, treatment with sodium tungstate reduced the germination percentage of the seeds slightly from $6 \%$ and $8 \%$. L-NAME was added after 0 tol 2 h of seed imbibition, and the seed germination percentage was significantly less $(P<0.05)$ (Fig. 2$)$.

\section{Discussion}

In response to sodium nitroprusside treatment, the seed germination percentage of empress trees was significantly greater, but there was no significant effect of $\mathrm{K}_{3}\left[\mathrm{Fe}(\mathrm{CN})_{5}(\mathrm{CO})\right]$ on the seed germination percentage of empress trees (Table 1, Fig. 1). Therefore, sodium nitroprusside works through NO to improve seed germination in empress trees.

Sodium nitroprusside promoted seed germination significantly in empress trees in low-light conditions (12 h of light) (Table 1). Similar effects of $\mathrm{NO}$ on photosensitivity have also been found in seeds of arabidopsis (Lindermayr et al., 2006) and lettuce 
[Lactuca sativa (Nicolás et al., 1996)]. NO-releasing compounds such as sodium nitroprusside, S-nitroso acetylpenicillamine, and 3-morpholinosydnonimine have also been shown to promote red light-stimulated princess tree seed germination (Giba et al., 1998).

Sodium nitroprusside promoted empress tree seed germination significantly in continuous light (Table 1 ), indicating that $\mathrm{NO}$ can release seed dormancy in empress trees. The greatest germination percentage of the seeds treated with only sodium nitroprusside was $56 \%\left(10^{-2} \mathrm{M}\right)$, which was still far below that in the viability tests $(97 \%)$, indicating that treatment with sodium nitroprusside alone did not break seed dormancy completely in the empress tree. Treatment with cold stratification for $96 \mathrm{~h}$ plus $10^{-4} \mathrm{M}$ sodium nitroprusside increased seed germination percentage significantly to $82 \%$ (Fig. 1). The dormancy of most of the seeds was broken by cold stratification for $96 \mathrm{~h}$ plus $10^{-4} \mathrm{M}$ sodium nitroprusside. NO has also been reported to break dormancy of other seeds. Previous studies on apple (Malus pumila) seeds found that in seeds treated with sodium nitroprusside after being stratified for $24 \mathrm{~h}$ at $5{ }^{\circ} \mathrm{C}$, the seed germination percentage was significantly greater (Gniazdowska et al., 2007). Sodium nitroprusside has great potential and is beneficial for the release of seed dormancy.

c-PTIO, sodium tungstate, and L-NAME had significant inhibitory effects on the seed germination of empress trees, and the extent of this inhibition was dependent on the time of absorption (Fig. 2). NR can produce NO under anaerobic conditions by using nicotinamide adenine dinucleotide as an electron donor (Yamasaki et al., 1999). Sodium tungstate can inhibit NR activity and inhibit NO synthesis. NOS stimulates L-arginine to synthesize NO (Calvo et al., 2004), and L-NAME inhibits NOS activity. This result shows that endogenous NO plays a crucial role in the release of dormancy of empress tree seeds during imbibition. When the endogenous $\mathrm{NO}$ is cleared, seed dormancy is maintained or even deepened. The c-PTIO treatment was imposed during the early stage of imbibition and had a stronger inhibitory effect on the seed germination of empress tree seeds. This result indicates that the endogenous NO that influences the seed germination of empress trees is produced mainly during the early stage of imbibition, which is consistent with previous studies on arabidopsis seeds (Liu and Zhang, 2009; Liu et al., 2010). In other words, the accumulation of endogenous NO during the early stage of absorption can promote the release of seed dormancy. The addition of sodium tungstate at $0 \mathrm{~h}$ of absorption showed the strong inhibitory effect, indicating that the endogenous production of NO may be related to the NR pathway.

The inhibitory effect of LNAME on germination does not imply the inhibition of NOS by LNAME, because if the NOS pathway requires a long time to produce $\mathrm{NO}$, then the NO produced after the absorption of water is cleared by c-PTIO; it also inhibits seed germination but mask any significant effect of c-PTIO later. In addition, if NOS produces NO continuously, the sooner L-NAME is used to treat seeds, the less NO is produced by NOS, and the stronger the inhibitory effect. However, our results did not show this trend. Therefore, L-NAME may inhibit the seed germination of empress trees by a means other than inhibiting NOS production of NO.

\section{Conclusions}

In conclusion, exogenous $\mathrm{NO}$ released seed dormancy and promoted seed germination in low light and continuous light. Sodium nitroprusside plus cold stratification can be used to break the seed dormancy of empress trees effectively. Endogenous NO was involved in the dormancy release and germination of seeds during the early stage of imbibition. Sodium nitroprusside is a cheaper alternative to $\mathrm{GA}_{3}$ for breaking dormancy and shortening the cold stratification time. Sodium nitroprusside is easy to purchase and use, and it can be used to germinate empress trees. Wider application of NO may be used for breaking seed dormancy in other species.

\section{Literature cited}

Association of Official Seed Analysts. 2010. Tetrazolium testing handbook. Assn. Official Seed Analysts, Washington, DC.
Beligni, M.V. and L. Lamattina. 2000. Nitric oxide stimulates seed germination and de-etiolation, and inhibits hypocotyls elongation, three light-inducible responses in plants. Planta 210:215-221.

Beligni, M.V. and L. Lamattina. 2001. Nitric oxide in plants: The history is just beginning. Plant Cell Environ. 24:267278.

Bethke, P.C., F. Gubler, J.V. Jacobsen, and R.L. Jones. 2004. Dormancy of arabidopsis seeds and barley grains can be broken by nitric oxide. Planta 219:847855.

Calvo, A.P., C.O. Nicolás, G. Lorenzo, D. Nicolás, and R. Dodríguez. 2004. Evidence for positive regulation by gibberellins and ethylene of ACC oxidase expression and activity during transition from dormancy to germination in Fagus sylvatica L. seeds. Plant Growth Regulat. 23:44-53.

Debeaujon, I. and M. Koornneef. 2000. Gibberellin requirement for arabidopsis seed germination is determined both by test characteristics and embryonic abscisic acid. Plant Physiol. 122:415-424.

Delledonne, M. 2005. NO news is good news for plants. Curr. Opin. Plant Biol. $8: 1-7$.

del Río, L.A., F. Javier Corpas, and J.B. Barroso. 2004. Nitric oxide and nitric oxidesynthase activity in plants. Phytochemistry 65:783-792.

Durner, J. and D.F. Klessig. 1999. Nitric oxide as a signal in plants. Curr. Opin. Plant Biol. 2:369-374.

Giba, Z., D. Grubišić, S. Todorović, L. Sajc, Đ. Stojaković, and R. Konjević. 1998. Effect of nitric oxide-releasing compounds on phytochrome-controlled germination of empress tree seeds. Plant Growth Regulat. 26:175-181.

Gniazdowska, A., U. Dobrzyńska, T. Babańczyk, and R. Bogatek. 2007. Breaking the apple embryo dormancy by nitric oxide involves the stimulation of ethylene production. Planta 225:10511057.

Jiménez, L., A. Rodríguez, J.L. Ferrer, A. Pérez, and V. Angulo. 2005. Paulownia, a fast-growing plant, as a raw material for paper manufacturing. Afinidad 62:100105.

Lamotte, O., C. Courtois, L. Barnavon, A. Pugin, and D. Wendehenne. 2005. Nitric oxide in plants: The biosynthesis and cell signaling properties of a fascinating molecule. Planta 221:1-4.

Lindermayr, C., G. Saalbach, G. Bahnweg, and J. Durner. 2006. Differential inhibition of arabidopsis methionine adenosyl 
transferases by protein S-nitrosylation. Biol. Chem. 281:4285-4291.

Liu, J., T.T. Xue, and Y.B. Shen. 2017. Seed dormancy and germination of Paulownia elongata in response to light, temperature, cold stratification, after-ripening and $\mathrm{GA}_{3}$. Seed Sci. Technol. 45:708713.

Liu, Y., N. Ye, R. Liu, M. Chen, and J. Zhang. 2010. $\mathrm{H}_{2} \mathrm{O}_{2}$ mediates the regulation of ABA catabolism and GA biosynthesis in Arabidopsis seed dormancy and germination. J. Expt. Bot. 61:29792990.

Liu, Y. and J. Zhang. 2009. Rapid accumulation of NO regulates ABA catabolism and seed dormancy during imbibition in Arabidopsis. Plant Signal. Behav. 4:905907.
López, F., A. Pérez, J.C. García, M.J. Feria, M.M. García, and M. Fernández. 2011. Cellulosic pulp from Leucaena diversifolia by soda-ethanol pulping process. Chem. Eng. J. 166:22-29.

Melhuish, J.H., C.E. Gentry, and P.R. Beckjord. 1990. Paulownia tomentosa seedling growth at different levels of $\mathrm{pH}$, nitrogen and phosphorus. J. Environ. Hort. 8:205-207.

Nicolás, G., D. Nicolás, and R. Dodríguez. 1996. Antagonistic effects of ABA and gibberellic acid on the breaking of dormancy of Fagus sylvatica. Physiol. Plant. 96:244-250.

Rockel, P., F. Strube, A. Rockel, J. Wildt, and W.M. Kaiser. 2002. Regulation of nitric oxide (NO) production by plant nitrate reductase in vivo and in vitro. $J$. Expt. Bot. 53:103-110.

Romero-Puertas, M.C., M. Perazzolli, E.D. Zago, and M. Delledonne. 2004. Nitric oxide signalling functions in plantpathogen interactions. Cell. Microbiol. 6:795-803.

Yamasaki, H., Y. Sakihama, and S. Takahashi. 1999. An alternative pathway for nitric oxide production in plants: New features of an old enzyme. Trends Plant Sci. 4:128-129.

Zhu, Z.H., C.J. Chao, X.Y. Lu, and Y.G. Xiong. 1986. Paulownia in China: Cultivation and utilization. Intl. Dev. Res. Ctr., Ottawa, Canada. 